\title{
El RelieVe Romano CON ESCENA NILÓtica APARECido en SAgunto. INTERPRETACIÓN DESDE UN PUNTO DE VISTA EGIPTOLÓGICO
}

Roman Relief with Nilotic Scene from Sagunto. Interpretation from an Egyptologic Point of View

MARÍA ENGRACIA MUÑOZ-SANTOS (0)

Dpt. Prehistòria, Arqueologia i Història Antiga. Universitat de València.maenmu@alumni.uv.es

RESUMEN:

Entre 2002 y 2004 se llevaron a cabo en Sagunto las excavaciones de la plaza de la Morería. Entre los muchos objetos que aparecieron, sobre una vía romana, estaba un relieve en mármol que, al ser levantado, mostraba una escena de las denominadas de tipo "nilótico". Este trabajo tiene como objetivo aportar algo más de información a la iconografía e iconología de un objeto excepcional.

Palabras clave: antiguo Egipto, relieve, Sagunto, Hércules

Abstract:

Between 2002 and 2004 excavations were carried in Sagunto, in the Plaza de la Morería. Many objects were found on a Roman road, including a marble relief, which showed a Nilotic scene. This paper gives more information about the iconography and iconology of that exceptional object.

Key words: ancient Egypt, relief, Sagunto, Hercules.

Copyright: $\odot 2017$ Maria Engracin Muñoz-Santos. This is an open access paper distributed under 
Entre junio de 2002 y 2004 se llevaron a cabo las excavaciones de la plaza de la Morería en Sagunto (Valencia). En la vía romana que circulaba junto al Circo, próximo a él, boca abajo, apareció este relieve, en un área cercana a una domus (Versluys y Seguí 2008: 342-343). En el mismo solar aparecieron más objetos como 70 teselas de mosaico de pasta vítrea, unos 300 fragmentos de mármol de revestimiento, muchos con molduras, pequeños fragmentos de esculturas de bronce, instrumental médico, estiletes para escritura, instrumentos musicales, amuletos fálicos, pequeños fragmentos de esculturas de mármol, restos de una fuente ornamental de mármol y además una cantidad de restos cerámicos (Melchor y Benedito 2004: 71).

\section{DESCRIPCIÓN}

Nos encontramos ante un relieve romano realizado en mármol de tipo Buixcarró (Cebrián 2008: 101-103) tallado en altorrelieve. Sus dimensiones son $30,8 \mathrm{~cm}$ de alto, $32,5 \mathrm{~cm}$ de largo y $3 \mathrm{~cm}$ de grueso. Con una moldura, tanto en la parte superior como inferior, de $3,5 \mathrm{~cm}$ de ancho, en el centro se representa una escena. Ha sido fechado entre los ss. II-III d.C. debido a su estilo, aunque fue encontrado junto con restos arqueológicos cuya fecha oscilaba entre los ss. II y IV d.C. (Melchor y Benedito 2004: 72).

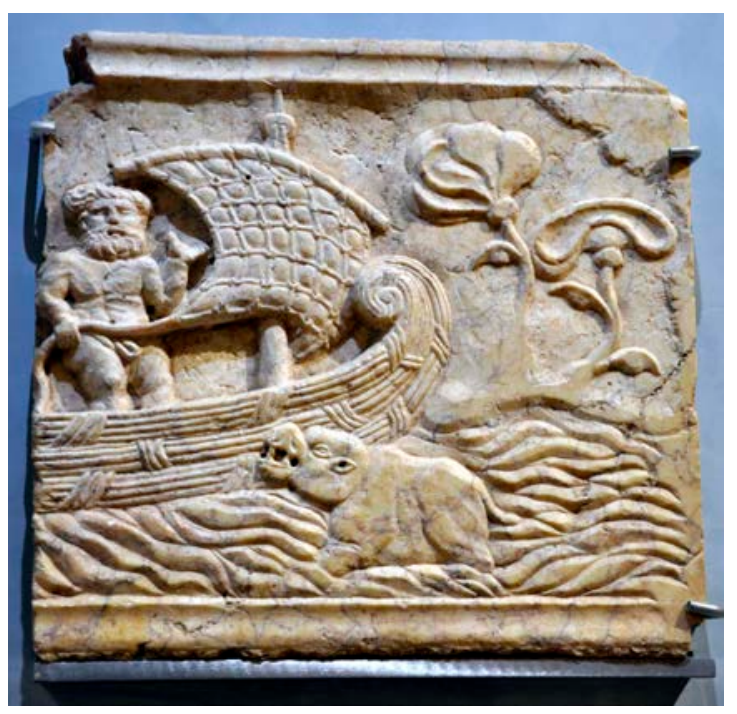

Fig. 1: Relieve objeto de estudio.
La pieza tiene forma cuadrangular y pertenecería a una mucho mayor, ya que parece que tiene continuidad a ambos lados donde se intuye que se ha quebrado. Su factura es de bastante calidad aunque la representación resulta algo tosca visualmente hablando, conociendo el gusto romano de la época. Se trata de una escena calificada como de "nilótica" por los autores anteriores.

La imagen puede dividirse en tres espacios diferenciados: el primero es el de un barco con una persona a bordo, el segundo el de una representación de agua con un hipopótamo y el tercero es donde aparece representado un motivo vegetal.

El barco es la parte que visualmente tiene mayor protagonismo y ocupa la mitad derecha de la escena. Vemos una embarcación que se ha representado muy detalladamente. Se aprecian los papiros y sus ataduras en haces y esa forma tan característica de la proa en forma de espiral. De esta forma eran construidas las balsas desde tiempo inmemorial en el valle del Nilo. Era un tipo de embarcación barata, de uso y vida muy limitado al sufrir la acción del agua directamente en el volumen del papiro que se hinchaba y deshinchaba según si estaba en el agua o fuera (Benito 2009: 35). Es característica esa forma como de cuchara (Wachsmann 2008: 29-30) y que es copiada en embarcaciones de madera, de mucha mejor calidad y más longevas, utilizadas por los monarcas y los dioses y que son las más representadas por los artesanos en los monumentos del Egipto antiguo. Esta embarcación incorpora un velamen que está completamente desplegado y que tiene forma cuadrangular, atado a un único mástil.

El personaje que se encuentra sobre la embarcación es algo peculiar. Como ya dejaron indicado en su momento (Versluys y Seguí 2008: 344) es una figura masculina, de pequeña estatura, desnuda y quizás algo deforme para el ideal de belleza del mundo romano, heredero del griego en gustos artísticos. A los mismos autores les recordaba vagamente a Bes, pero descartan a este dios por la falta de sus elementos característicos: el tocado de la cabeza, por poner un ejemplo sencillo. Es musculoso aunque está representado de forma bastante grosera y el cuerpo tiene una ligera desproporción con respecto a la cabeza, está desnudo y muestra el sexo sin pudor perfectamente representado. Tiene una abundante barba y luce en la cabeza una importante mata de pelo. Sujeta uno de los cabos de la vela con la mano derecha, mientras mantiene la izquierda elevada. Parece que tiene las piernas en una posición apropiada para absorber los movimientos de la embarcación. 
El segundo espacio de la escena está ocupado por el agua, que ha sido representada por el artesano con formas onduladas, como si hubiese cierto oleaje. Esta parte de la escena ocupa prácticamente la mitad inferior de la representación. Dentro del agua se encuentra un hipopótamo, que asoma todo su cuerpo por encima, a excepción de la parte inferior de las patas. Esta figura tiene también una desproporción muy importante con respecto a la embarcación, siendo de unas dimensiones mucho más pequeñas para lo que este animal ocuparía realmente.

El último espacio lo ocupa una decoración floral, que queda a la izquierda del relieve y consiste en dos grandes flores que casi ocupan un cuarto de la escena. De factura mucho más delicada, pero que parece inconclusa en la parte inferior de los tallos, aunque sí comenzó a trabajarse.

\section{LECTURA DE LA IMAGEN}

Por lo tanto, la escena tiene cinco aspectos muy destacables, que son los que nos dan la pista para poder interpretar la imagen: el agua, el hipopótamo, el barco de papiro con la vela desplegada, el personaje que lo gobierna y las dos grandes flores. Todo ello nos anuncia que se trata de una escena nilótica, como ya mencionábamos más arriba, pero podemos profundizar mucho más en la imagen para, quizás de esta forma, entender lo que se representa.

En el antiguo Egipto tanto el Nilo como la barca tenían una fuerte carga simbólica, ya fuese en la vida como en la muerte. El Nilo, mediante su crecida, proporcionaba vida, puesto que con el limo que acarreaba y que depositaba en su desbordamiento, ayudaba a que los campos tuviesen fértiles cosechas, de estos campos dependía la vida de toda la población egipcia. Además, era el símbolo del viaje al más allá, este se realizaba en una embarcación que era gobernada por los dioses y que transportaba al difunto de un lado al otro del río Nilo, es decir, desde la vida hacia la muerte. El río y las embarcaciones, por tanto, eran un claro e inequívoco signo del mundo egipcio que se transmitió por todo el Mediterráneo, un hito que lo diferenciaba de otros lugares del mundo conocido en época antigua. Roma utilizó la imagen del Nilo desbordado para representar el exotismo de Egipto en muchas ocasiones, tenemos varios ejemplos en Pompeya. Durante los ss. I y II d.C. se convirtió en uno de los temas favoritos con los que decoraban sus domus los romanos.
Aunque la embarcación es típicamente egipcia, debemos fijarnos en la vela. Los barcos egipcios, según sus representaciones artísticas, tenían velas lisas y cuadradas o rectangulares, probablemente tejidas con lino, fibra de papiro o algodón. Estas se ataban a un mástil central, el único de la embarcación, de él pendía la verga y la botavara, que eran otros palos que se situaban de forma perpendicular al mástil. De la parte superior del palo central surgían las maromas para dominar el velamen (Vinson 1994: 37-ss.). Pero no es el caso de la imagen que estamos describiendo. Aquí vemos que la vela está surcada por cabos anudados unos a otros, que le dan un aspecto de cuadrícula. Se trata de algo extraño en el mundo egipcio, pero muy usual en el mundo romano y que podemos apreciar en mosaicos, por poner un ejemplo, el del templo de Ceres en la Plaza de las Corporaciones en Ostia Antica. Estos cabos corrían por la parte delantera de la vela, guiados por un sistema de anillos cosidos a esta de forma que podía ser recogida a modo de persiana veneciana. El aspecto cuadriculado se lo daban las cuerdas de refuerzo, tanto verticales como horizontales, que cubrían la tela (Whitewright 2016: 879).

La representación del agua no es de estilo egipcio. Los artesanos del Nilo cuando representaban el agua del Nilo lo hacían de forma canónica: innumerables líneas en zig-zag paralelas, bien en horizontal o bien en vertical. En el relieve de Sagunto aparece un oleaje desigual, con líneas desordenadas, que ayudan a dar la sensación de realidad y parece que representa un Nilo en movimiento.

El hipopótamo y su posición, en la parte izquierda inferior de la escena, ha sido representado de forma muy desproporcionada, podríamos pensar, en principio, que se debe al intento de utilización de una perspectiva, pero sería un error, puesto que en este caso su tamaño tendría que ser mucho mayor que el realmente representado. Lo que sí podemos acertar a decir es que está en una zona poco profunda del Nilo, posiblemente porque represente que está próximo a la orilla, ya que si estuviese más cerca de la embarcación, estaría mucho más hundido. Entre el personaje y el hipopótamo parece que hay un diálogo puesto que ambos están encarados e incluso parece que el personaje masculino lo saluda con la mano izquierda levantada, el hipopótamo además abre la boca, quizás en señal de respuesta. Podría pensarse que, en realidad, es una escena de ataque del animal, pero la imagen general no es de violencia, sino de paz, con muy poco movimiento. 
El caso de las flores es también bastante particular. Son dos flores de loto. Puesto que no aparece ningún paisaje al fondo, podríamos deducir que se trata de tierra firme o del puerto a dónde quiere llegar el viajero. Que estén representadas como flotando en el aire puede ser debido a que esté inacabado el trabajo, pero también a que se trate de la representación de una idea y no de un lugar concreto, el Sur.

\section{NUESTRA INTERPRETACIÓN}

Interpretar una pieza como esta no es algo fácil puesto que se une la iconología y la iconografía egipcia tradicional con la reinterpretación hecha por el entendimiento romano, adaptado todo ello al dueño que, debido a la factura, probablemente no era egipcio. Lo que sí podemos aventurar es una posible lectura e interpretación de la escena.

Nos encontramos ante una representación de un viaje por el Nilo de una pequeña embarcación, pobre, de uso común entre los egipcios, cosa que sabemos por el material con que está realizada. Por los datos que nos da la escena, deducimos que el viaje se hace de norte a sur. Esto lo imaginamos puesto que el loto era el símbolo del Alto Egipto desde tiempo inmemorial en la historia del país del Nilo y tanto la embarcación, como la vela y el personaje están representados de cara a los lotos, es decir, en dirección a ellos. El que tenga las velas desplegadas es otra prueba de su dirección hacia el Sur ya que eran innecesarias si se viajaba a favor de la corriente (de S a N) pero imprescindibles para remontarla si se hacía en contra (de $\mathrm{N}$ a S). La vela se desplegaba para poder recoger la fuerza de los vientos Etesios que soplan desde el Delta hacia el interior de África, esta circunstancia meteorológica ocurre siempre en verano, debido al calentamiento de la zona. Puesto que no está representada tierra firme, ya que no ha sido trabajado el mármol en la zona donde debería aparecer, nos hace sospechar que se ha querido representar la crecida del Nilo, con el agua llegando hasta el horizonte. Son dos datos interesantes (los vientos Etesios así como la crecida) para situar la escena en una posible estación del año. Ambos efectos meteorológicos coincidían entre los meses de junio y septiembre y el pico de la inundación se daba a finales de agosto.

Los dos protagonistas de la imagen son también muy interesantes. Como más arriba decía y también apuntaron en su texto Versluys y Seguí, el personaje masculino nos sugiere un recuerdo al dios Bes (Wilkinson 2003: 102-104). Este dios era representado por los egipcios, tradicionalmente, con el rostro chato y leonino (Franco 2000: 24) y era el único que no aparecía de perfil, ya que siempre se representaba de cara. Era el dios protector de las parturientas y se utilizaba como imagen apotropea, ya que se creía que expulsaba a los malos espíritus. Pero como ya decíamos, no tiene los atributos de este dios, le faltan algunos detalles como las tan conocidas características físicas, la lengua fuera en mueca burlona y el tocado de la cabeza. Esto podría ser debido a que realmente se trata de la imagen de Hércules (Melchor y Benedito 2004: 7), el griego Heracles que es asimilado a Bes (Blakely 2006:148; Larson 2007: 183 187; Gómez 2001-2002: 91-106; Bonnet 1985: 231-240). Leemos en Heródoto: Yo tengo muchos indicios de que los egipcios no han tomado de los griegos el nombre de Heracles, sino los griegos de los egipcios (II $43,1)$ y da como prueba que Heracles es de Egipto diciendo que: sus antepasados los padres del Heracles griego, Anfitrion y Alcmena, eran ambos oriundos de Egipto (II 43,2). Este dios Bes, que es asimilado al héroe y dios Heracles griego, podría haber pasado asimilado entonces como Hércules a la cultura romana. Su aspecto es vigoroso y fornido como ya destaca, por poner solo un ejemplo, Hesíodo en su Teogonía (290) y es algo que han querido resaltar profusamente en el relieve, puesto que este personaje es el principal de la historia que narra la escena.

Además, es interesante la elección de un hipopótamo y no un cocodrilo, animal quizás mucho más conocido y característico del río para un romano. Aunque la escena se ha interpretado como un Hércules en su partida victoriosa del Jardín de las Hespérides con las manzanas de oro (Melchor y Benedito 2004: 72) no lo creemos plausible, puesto que las Hespérides no se situaban en Egipto, sino al otro extremo del Mediterráneo, en el Oeste (Hesíodo Teogonía 215), creemos que la elección del hipopótamo es importante para la comprensión de la escena y seguimos destacando la relación que hay entre ambos personajes. Que no aparezca ningún elemento característico de occidente tampoco da pie a entender que sea el viaje de uno a otro lado del Mediterráneo, como apunta Fernández (2014: 99).

Fernández (2014: 103) habla del mito relatado por Ferécides donde nos dice que: Desde ahi el héroe pasa a Libia, donde mata a Ateneo, hijo de Poseidón. Seguidamente llega a la ribera del Nilo, en Menfis, 
donde mata a Busiris, otro hijo de Poseidón. Después de haber remontado el río hasta Tebas, se dirige hacia Libia exterior por la montaña, matando numerosas bestias salvajes del desierto (Ferécides, FGrHist 3 F16a). Menfis se encontraba al S del Delta del Nilo y Tebas en el curso medio del Nilo, era la antigua Luxor y fue una de las capitales más importantes de la historia del antiguo Egipto. Curiosamente son nombradas las dos capitales históricas del país del Nilo, donde estuvo establecida la monarquía. El relieve, por lo tanto, podría hacer referencia a ese viaje entre Busiris y Tebas, y el sentido de la marcha sería de $\mathrm{N}$ a S, entre la victoria contra Busiris y el momento en que se pone en marcha hacia su segunda escala remontando el Nilo.

No creemos que la elección del hipopótamo sea azarosa. El hipopótamo era considerado en la antigüedad egipcia un animal temido, puesto que destrozaba los cultivos, en su versión masculina, era la manifestación del desorden, y, por lo tanto, del mal. Fue representado siendo cazado por los nobles durante el Reino Antiguo. Después del Reino Nuevo probablemente había desaparecido de las orillas del río (Corteggiani 2010: 245) Incluso fue equiparado al propio Seth (Wilkinson 1998: 73). El hipopótamo, por lo tanto, era el mal. Pero tenía una parte más positiva, la hembra, gran defensora de su cría. La diosa Taweret (Wilkinson 2003: 185-186) se representaba siempre bajo la imagen de este animal. Era la diosa de la fertilidad y la reproducción. Era una divinidad muy popular, velaba por las parturientas. Curiosamente, y de nuevo este hecho puede ayudarnos a entender la imagen, aparecida algunas veces acompañada del dios Bes (Franco 2000: 119) protagonizando danzas para celebrar el nacimiento del bebé (Corteggiani 2010: 644-646). Taweret era la protectora del hogar y tenía una relación directa con el Nilo debido tanto a la fertilidad de la parturienta con la crecida como por el agua desbordada y la ruptura de aguas de la futura madre. Taweret y Bes eran un matrimonio divino según la mitología egipcia. Por lo tanto se trata de un animal ambivalente, y según su representación, tenían un significado en Egipto: el hipopótamo recostado sobre sus patas traseras representaba aspectos positivos, cuando estaba erecto sobre sus cuatro patas, su imagen daba a entender hostilidad (Wilkinson 1998: 73).

Sin duda, se trata de una pieza singular tanto por su temática como por el lugar donde fue encontrada.

\section{CONCLUSIONES}

Podemos concluir entonces que se trata de un relieve de temática nilótica pero de factura romana, debido a la representación tan realista de la embarcación como del hipopótamo, el artesano debía conocer suficientemente bien Egipto. Su buena técnica adolece de un dibujo de las figuras algo tosco, así que no sería de un taller artesanal importante y un producto demasiado caro. El hecho de que esté realizado en mármol de Buixcarró, y que no hayan aparecido hasta el momento más piezas como esta, nos induce a pensar que sería un encargo excepcional de un habitante de la zona o un templo.

Debido al gusto de los romanos por aquellos dioses apotropeos para expulsar de sus hogares el mal de ojo y los malos espíritus y el gusto por lo exótico y del mundo egipcio, no es extraño que una imagen como esta apareciese en un contexto romano, ejemplo de escenas nilóticas han aparecido en Pompeya o Roma, aunque que lo hiciese en Sagunto sí es algo extraordinario. Nuestra interpretación solo es un intento de lectura del relieve, de arrojar algo de luz a tan enigmática imagen. Por supuesto, desconocemos si el ciudadano de Saguntum que encargó esta pieza podía conocer a estos dioses egipcios o si podía darles el mismo significado que hemos expuesto aquí. Lo cierto es que por la factura del hipopótamo y del barco de papiro, pensamos que si el cliente no conocía el mito, quizás el artesano sí, puesto que la calidad de los detalles en esos dos detalles son los de alguien que conoce el lugar.

La importante relación que había entre el héroe Hércules y Sagunto (Pérez 1990: 23 y ss) es de destacar por el hecho de que una pieza así se encontrase en la ciudad. Como dice esta autora, Sagunto fue considerada una fundación de Hércules en honor de uno de sus compañeros de expedición, de ahí también la importancia de la Vía Heraklea en la ruta, que ya en época de este relieve sería Vía Augusta. Es sabido que en la ciudad había un templo dedicado al héroe deificado. Podría ser parte de su decoración como bien apunta la autora (Fernández 2014: 101).

La pieza perfectamente podría haber pertenecido a un friso decorativo o bien un pinax, elementos que gustaban mucho a los romanos para sus atrios y de los que existen otros ejemplos con la misma temática, como el que se encuentra en el Museo de Princeton (num. Inv. y1962143). En este caso, al encontrarse incompleto y puede que inacabado, no podemos darle una verdadera utilidad. 
Probablemente, en el momento de acabarse, se hubiese pintado con colores vivos, lo que le hubiese dado una imagen muy vistosa y decorativa para la zona pública de una domus rica de la zona de Sagunto.

\section{BIBLIOGRAFÍA}

BENITO, J. M. (2009): La barca solar en el arte del antiguo Egipto, Ars Longa 18, 33-50.

BLACKELY, S. (2006): Myth, Ritual and Metallurgy in Ancient Greece and Recent Africa, Cambridge .

BONNET, C. (1985): Melqart, Bès et l'Héraclès Dactyle de Crète (E. Gubel, E. Lipinski) Phoenicia and its neighbours, Peeters.

CEBRIÁN, R. (2008): Saetabis y el comercio del Buixcarró, Lucentum 27, 101-113.

CORTEGGIANI, J.-P. (2010): El gran libro de la mitología egipcia, Madrid.

FERNÁNDEZ, M. (2014): Relieve nilótico del siglo II-III d.C. Análisis sobre un relieve hallado en la Vía del Pórtico, Braçal 49, 95-112.

FRANCO, I. (2000): Pequeño diccionario de Mitología egipcia, Madrid.

GÓMEZ, D. (2001-2002): Bes y Heracles: estudio de una relación, Estudios Orientales 5-6, 91-106.

LARSON, J. L. (2007): Ancient Greek Cults: A Guide, New York.

MELCHOR, J. M.; BENEDITO, J. (2004): La excavación del solar de la Calle Huertos-Calle Alorco-Plaza Morería de Sagunto: Avance de los resultados, Arse 38, 63-80.

PÉREZ, L. (1990): El origen de Sagunto en Silio Itálico, Arse 25, 23-39.

VERSLUYS, M.; SEGUÍ, J. J. (2008): A newly discovered relief from Saguntum, Madrider Mitteilungen 49, 341-353.

VINSON, S. (1994): Egyptian boats and ships, Princes Risborought.

WACHSMANN, S. (2008): Seagoing Ships \& Seamanship in the Bronze Age Levant, College Station.

WHITEWRIGHT, J. (2016): "Ships and boats", (G. L. Irby) Companion to Science, Technology, and Medicine in Ancient Greece and Rome, vol. 1, Oxford.

WILKINSON, R. H. (1998): Cómo leer el arte egipcio, Barcelona.

WILKINSON, R. H. (2003): The complete gods and goddnesses of Ancient Egypt, London 